\title{
Active Stiffness Method for High Cycle Fatigue Mitigation using Topical Thin Foil Shape Memory Alloy
}

\author{
Nicholas G. Garafolo*, Rachel Collard \\ Department of Mechanical Engineering, The University of Akron, Akron, OH 44325, U.S.A. \\ *Corresponding author: nicholas.g.garafolo@uakron.edu
}

\begin{abstract}
The strong need for high cycle fatigue mitigation has resulted in numerous techniques resulting in added weight, increased operational costs, and lower performance. The experimental investigation presented was a foundational effort towards mitigating HCF through the use of shape memory alloy in a composite system. The research objective was to quantify changes in eigenvalue, eigenvector, and amplitude of a vibrating cantilever beam with a thin SMA topical treatment; as quantified during SMA phase transformations and through comparison with a control. A composite beam consisting of a nitinol thin SMA foil adhered to an Aluminum Alloy 6061 substrate was designed and fabricated. The three configurations were utilized: (1) a full-span SMA treatment designed for maximum eigenvalue shift and maximum amplitude reduction, (2) a half-span SMA treatment designed for eigenvector shift, and (3) a full-span aluminum treatment for a control. Through a complete modal analysis, results illustrated that thin foil SMA treatments led to a significant shift in eigenvalue, up to 6.53\%. Highlighting the reduction in amplitude was a 92\% reduction in amplitude at second bending with constant excitation frequency with the full-span sample. Spanwise scans on the half-span sample with and without SMA actuation illustrated a $0.77 \%$ shift in node location.
\end{abstract}

Keywords: shape memory alloys, thin foil, vibration, high cycle fatigue, turbomachinery

Cite This Article: Nicholas G. Garafolo, and Rachel Collard, “Active Stiffness Method for High Cycle Fatigue Mitigation using Topical Thin Foil Shape Memory Alloy.” Journal of Mechanical Design and Vibration, vol. 5, no. 1 (2017): 11-20. doi: 10.12691/jmdv-5-1-2.

\section{Introduction}

Emerging materials and unique methods for their implementation are vital for the success of novel high cycle fatigue (HCF) mitigation methods. One such class of material displays a shape memory effect and is classified as shape memory alloys (SMA) [1]. After being deformed at a lower temperature, these alloys will return to their undeformed shape when heated to a higher temperature. This behavior is due to a solid-solid phase change in the material from martensite to austenite. The introduction of the shape memory effect, whereby the shape memory alloy material acts as both a damper and a means of variable stiffness is a novel technique for HCF mitigation [2,3].

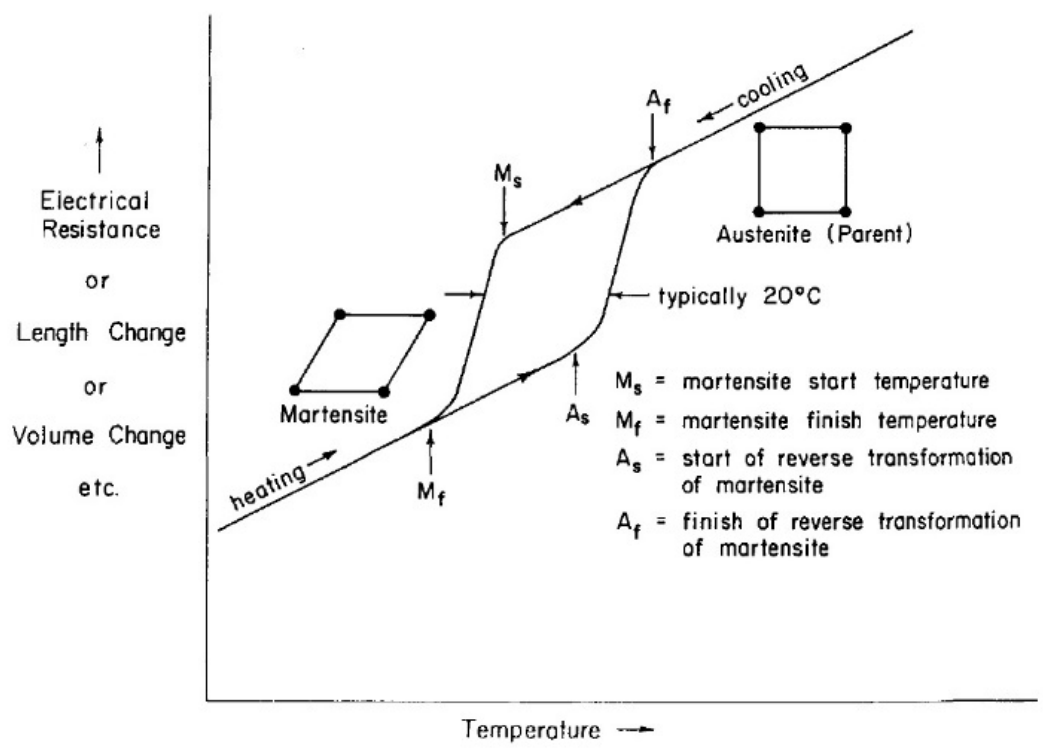

Figure 1. Hypothetical property change in shape memory alloy [1] 
Shape memory alloys have the distinguishable ability to undergo a solid-solid phase transformation. During this solid-solid transformation between martensite and austenite, SMAs exhibit changes in numerous properties (e.g., electrical resistance, length, volume), illustrated Figure 1 [1]. Here, the phase transformation is evident in the non-linear property response. As the sample is heated, a nonlinear property change is evident at the austenite start temperature $\left(\mathrm{A}_{\mathrm{s}}\right)$ and continues until it reaches the austenite finish temperature $\left(\mathrm{A}_{\mathrm{f}}\right)$. Further heating is shown as a linear response. Upon cooling, the non-linear property change is evident at the martensite start temperature $\left(M_{s}\right)$ and continues until it reaches the martensite finish temperature $\left(\mathrm{M}_{\mathrm{f}}\right)$. These changes are extended to include changes in elastic modulus.

It has been shown that the variability in stiffness, induced by changes in elastic modulus inherent to shape memory alloys, has the capability of shifting the eigenvalues (i.e., modal frequencies) of components made with this material. This active stiffness lends itself towards the mitigation of high cycle fatigue in turbomachinery, characterized by high frequencies, low amplitudes, cyclic elastic behavior, and high cycle count. Engine failures due to HCF have been experienced in both domestic and international commercial engines, as well as determined to be the primary cause of several failures of USAF fighter engines [4]. Numerous studies exist illustrated changes in natural frequency through embedded SMA wires in composite structures [5,6,7]. In additional, variable stiffness has been shown to reduce component amplitudes and create a change in the eigenvectors (i.e., mode shape vector) [2]. Modeling has afforded the ability to understand the fundamental nature of these systems [8,9]. Amplitude control methods have also been achieved through electromagnetic actuators [10]

Damping can be used to mitigate the excessive stresses in engine components that lead to high cycle fatigue [11]. The design of advanced, high performance turbomachinery blades, such as bladed disks, has led to higher stresses and decreased damping. Means to obtain additional damping cannot interfere with the aerodynamics of machinery blades, so any treatments must be internal, out of air flow, or in the form of a thin layer. Advances in manufacturing techniques have enabled integrally bladed disk designs. These designs are highly susceptible to high cycle fatigue as they are inherently low damped [12].

Nickel Titanium (NiTi, Nitinol), a common commercially available SMA, has shown damping an order of magnitude higher than ordinary metals [13]. The composition of the $\mathrm{NiTi}$ alloy and the thermo-mechanical processing influence the damping characteristics of the material [11]. In addition, the transformation temperature can be tailored through formulation, especially for high temperature applications $[14,15] ; \mathrm{Ni}_{19.5} \mathrm{Ti}_{50.5} \mathrm{Pd}_{25} \mathrm{Pt}_{5}$ has a transformation temperature near $300^{\circ} \mathrm{C}$, which is conducive for turbomachinery applications [16].

Shape memory alloys allow for large amounts of recoverable strain which coincide with work densities that can be ten times higher than traditional approaches [1]. The shape memory effect allows for the use of shape memory alloys in applications where work per unit weight must be maximized. The density of NiTi is $6.45 \mathrm{~g} / \mathrm{cm}^{3}$, slightly higher than the $4.43-4.66 \mathrm{~g} / \mathrm{cm}^{3}$ density of current titanium alloys used in aero engine components [17]. Shape memory alloys can be used for multiple activations. If the material is returned to its original state, it can be deformed, reheated, and recovered repeatedly [1].

Duffy et al. found that SMAs exhibit damping during their phase transformation. When an SMA is in the austenite phase and is slightly above a prescribed temperature, the addition of an external stress can produce the martensite phase. The amount of damping observed depends upon the steady state stress level, alternating stress level, frequency, and temperature [16].

The objective of the research presented was to quantify the effectiveness of a thin foil NiTi SMA topical treatment as a potential high cycle fatigue mitigator by first looking at its ability to create variable stiffness in a cantilever beam. Through a series of experimental analyses the effects of the variable stiffness, most notably eigenvalue frequency shift, decrease in amplitude, and node location shift, were quantified.

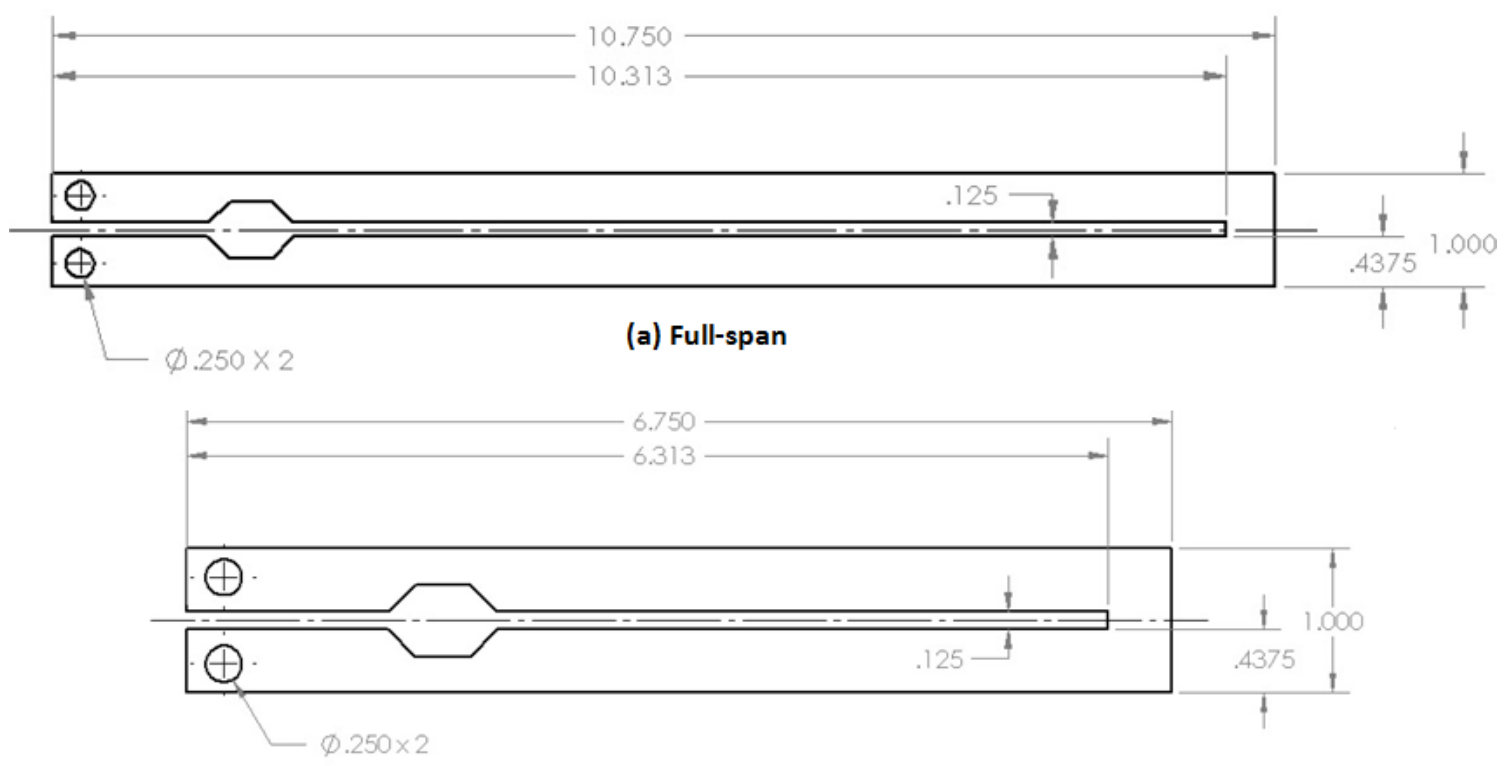

(b) Half-span

Figure 2. Dimensions of topical treatments for the (A) full-span length and (b) the half-span length 


\section{Experimental Design}

Repeated experimental analyses were performed on a cantilever beam in a fixed-free condition. By adopting this specimen type, this research leverages an extremely large experimental and theoretical base.

\subsection{Test Specimen}

The test specimens consisted of a topical treatment adhered to an aluminum substrate. The specimens were designed to have a free length of 8 in. when clamped to a dynamic shaker. The overall dimensions of the aluminum specimens was 11 in. $x$ in. $x 0.125$ in.

Three topical treatment were fabricated. The dimensions of the topical treatment are illustrated in Figure 2; further differentiated in length as "full-span" and "half-span". The experiment test specimens consisting of one "half-span" and one "full-span" were created from shape memory alloy sheet material NiTi. The experimental control was fabricated from aluminum topical sheet in only the "full sample" configuration. The shape memory topical treatment consisted of $\mathrm{Ni}_{55} \mathrm{Ti}_{45}$ and was received as factory annealed flat. The selected SMA configurations were cut out of the 0.008 in thick shape memory sheet material by a waterjet. The treatments were not subjected to any additional heat training. Certificates of material data accompanying the shape memory alloy sheet material listed the modulus of the material as 28-41 GPa for the martensite phase and $83 \mathrm{GPa}$ for the austenite phase. The austenite finish temperature of the material was listed as $113^{\circ} \mathrm{C}$. The control topical treatment consisted of Aluminum 1145-H19 and was 0.008” thick.

The substrate of the test specimens consisted of a beam, machined from 0.125 in. aluminum alloy 6061 sheet material. Again, the specimens were designed to have a free length of 8 in. when clamped and an overall dimensions of 11 in. $x 1$ in. $x 0.125$ in.

The SMA treatments were adhered to one side of the aluminum alloy beams using Permabond 920 high temperature cyanoacrylate. The treatments were designed to be fully adhered to the 8 in. free length of the beam while also being applied to the section of the beam that ran under the clamp so that the SMA could be attached to leads on the opposite side of the clamp. The composite samples underwent a full curing process to leverage the high temperature properties of Permabond 920. During this process the samples were brought to $150^{\circ} \mathrm{C}$ for two hours in an oven. Prior to the adhesion process, the aluminum beam specimens were anodized to electrically isolate them from the SMA treatments. Continuity testing of the anodized aluminum substrates and SMA treatments in the adhered condition ensured the electrical isolation between the components. The experimental control consisted of a thin aluminum foil, adhered to the same anodized aluminum substrate. Composite samples can be seen in Figure 3.

\subsection{Technical Approach}

The SMA topical treatments on the beams were brought through the austenite finish temperature of $113^{\circ} \mathrm{C}$ with the use of a DC power supply. Leads were attached to either end of the SMA loop on the opposite side of the dynamic shaker clamp so as to not interfere with vibratory testing. Temperature readings of the SMA treatments were taken by an infrared temperature sensor and the information was fed to a data acquisition system. A LabVIEW controller used the feedback data and a specified target temperature to control the SMA surface temperature by varying the current that was flowing through the treatment.

The infrared sensor was previously calibrated using a small coupon of thin SMA material. An E type thermocouple was attached to the surface of the sample using thermal grease and Kapton tape. The infrared temperature sensor was set up on the other side of the sample directly opposite the thermocouple, leveraging the heat transfer properties of the slender sample. The sample was heated with a heat gun until the thermocouple read approximately $160^{\circ} \mathrm{C}$ at which time the heat gun was turned off and data sampling began. Eight tests were run and for each test a plot was constructed of time value points of infrared voltage output versus thermocouple temperature. A linear curve fit was taken for each test and the resulting coefficients were averaged to construct an overall equation. This equation was then used in the LabVIEW controller to convert the infrared sensor output voltage to SMA surface temperature.

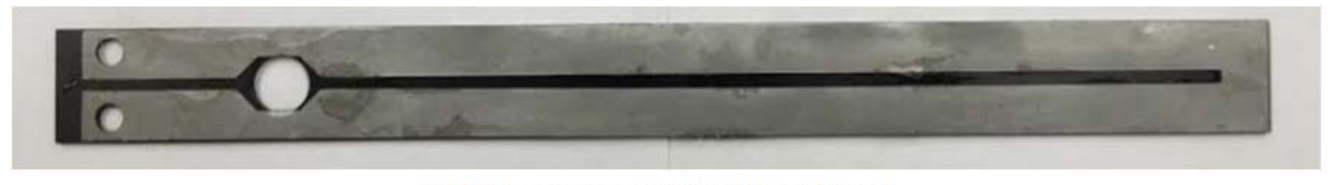

(a) Full-span sample adhered to substrate

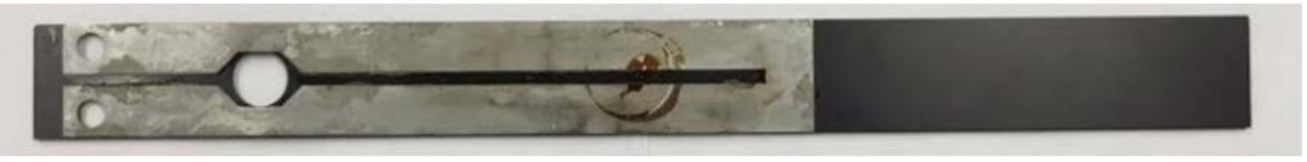

(b) Half-span sample adhered to substrate

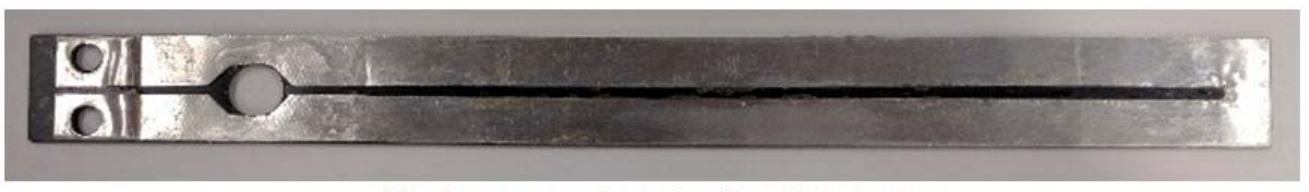

(c) Full-span control sample adhered to substrate

Figure 3. Composite experiment samples (a) and (b), consisting of an anodized aluminum substrate with nickel titanium topical treatment. Composite control sample (c), consisting of anodized aluminum substrate with aluminum topical treatment 


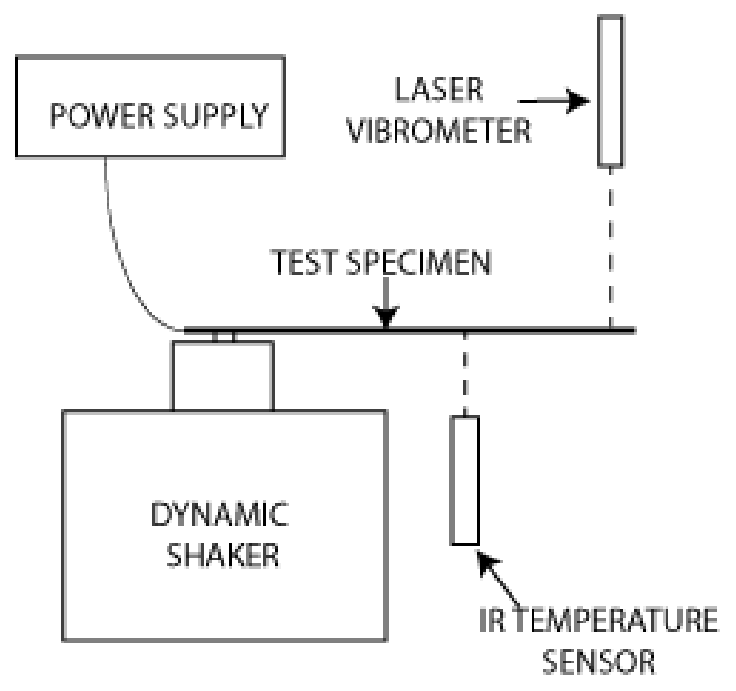

Figure 4. Experimental setup of dynamic shaker, composite beam, and infrared temperature sensor

Using a dynamic shaker, an accelerometer attached to the top of the clamp, and a Polytec Scanning Laser Vibrometer, tests for each sample were performed while the SMA treatment was both actuated and unactuated. The samples were clamped on one end by the dynamic shaker. The other end was free. The clamp was designed with phenolic inserts to electrically isolate the composite samples from both the clamp and the dynamic shaker. A Teflon washer was used to further isolate the clamp's center bolt from the SMA treatment. Test setup is illustrated in Figure 4.

\subsection{Data Reduction Technique}

The experimental vibration investigation included a complete modal analysis over the selected frequency range of $50-2000 \mathrm{~Hz}$. This range was selected to avoid first bending mode, which results in significant strains at the beam root and also high amplitude at the beam tip making velocity data difficult to capture, while capturing bending modes 2, 3, 4, and 5 .

The Polytec scanning laser vibrometer obtained velocity response data from the samples and input data from the attached accelerometer. Software performed a Fast Fourier Transform (FFT) to map the time domain data to the frequency domain and took the ratio of the response to the input data to calculate the Frequency Response Function (FRF). The FRF was used to find the peak frequencies and displacements of the modes studied.

\subsection{Error Analysis}

The data was taken at a bandwidth of $2000 \mathrm{~Hz}$ with 6400 FFT lines. Uncertainty for frequency was equal to half of the resolution of the FFT giving a frequency uncertainty of $\pm 0.156 \mathrm{~Hz}$. The error in the frequency response of the scanning laser vibrometer decoder was $\pm 0.1 \mathrm{~dB}$. The resolution of the laser's data acquisition system was 16 bit. The non-linearity in the shear accelerometer was less than $1 \%$. Repeated tests resulted in a student $t$ value of 2.228 for a 95\% confidence window. The bias error of the scanning laser vibrometer is negligible compared to the precision error in the tests.

\section{Results and Discussion}

Shaker amplitude was set to a constant value during these experiments. The composite beams did not appear to develop static curvature at high temperature. Such curvature would affect dynamic results. While experimentation was preliminary, and designed to facilitate simple manufacturing of composite samples, future experimentation could benefit from embedding SMA material into the center of the beam.

Due to equipment availability, repeated tests were completed using two different methods. All of the data for the full-span sample, and scans 9 and 10 for the half sample were completed using a scanning laser vibrometer and associated Polytec software to generate input, create an FFT of laser output data, and detect and quantify modal peak frequencies. The scanning laser vibrometer was only used to take data at one point, at the beam tip. The remaining half sample repeated test data was preformed using a single point laser, a signal generator input, and a LabView program to complete an FFT of laser data and quantify modal peaks. Both methods used the same input frequency sweep and amplitude and led to complementary data. The second method did not utilize data filters so some stray points were encountered. Representative data scatter for the scans and temperature sweep is illustrated latter in Figure 7 and Figure 8. Here, the difference between individual temperature sweeps is shown. Note, more data points are presented for the half sample because, with an exception for scans 9 and 10, the data was sampled at a faster rate.

Joule heating was used as the catalyst in obtaining the original shape from the deformed SMA. Employing this method allowed for a low power mechanism to return the SMA treatment to its original state and orientation. Low weight is inherent to the use of SMAs because they can be directly actuated without extra parts [1]. It is expected that optimally designed components will be of low weight and low power consumption (using a method other than joule heating), and thus attractive for future use in flight applications. Alternatively, SMA formulations exist with high temperature transformation temperatures $[14,15,16]$; utilization of the engine operating temperature may be a viable source of actuation.

\subsection{Eigenvalue Shift}

The key area of interest was the use of SMAs to shift the natural frequency (i.e., eigenvalue) of a component. This would allow for the natural frequency of a component to be moved away from potential trouble spots through the use of an SMA actuator. The data shows a consistent and quantifiable shift in frequency between actuated and unactuated treatments in both full-span and half-span sample configurations over all of the bending modes tested.

Experimentally, single point data was taken with the scanning laser vibrometer at the beam tip of each sample while the topical treatment was brought from room temperature to activation temperature and then back down to room temperature. This test was used to quantify the effect of the SMA treatment's hysteresis loop on the sample's modal frequencies. Full scans were taken of the 
half sample using the scanning laser vibrometer while the topical treatment was brought to $110^{\circ} \mathrm{C}$ and $135^{\circ} \mathrm{C}$ to evaluate any change in node location.

A typical map of the eigenvalues during vibratory response is shown in Figure 5. As temperature increased, the substrate softened resulting in a reduction in stiffness and a lower eigenvalue. As the temperature approached the austenite start temperature, the composite test specimen experienced are significant increase frequency. This increase dominated any expected losses in frequency due to substrate softening. The increase in frequency continued until the austenite finish temperature, where a drop in frequency was observed during softening of the SMA topical treatment. During cooling, the test specimen increases stiffness until the martensite start temperature, where a sharp drop in frequency was observed. The typical hysteresis nature of the SMA phase transformation process was illustrated by comparing the heating and cooling cycles. The measurement uncertainty of the eigenvalue map is also illustrated in Figure 5.

The experimental control (topical aluminum foil on aluminum substrate) illustrated the fundamental nature of the aluminum substrate. As temperature increases, the aluminum substrate softened. This reduction in material stiffness was illustrated by a significantly drop in the nature frequency for the vibrating beam, Figure 6. It is important to note the "knee" in the curve around $115^{\circ} \mathrm{C}$. It is suggested that inflection was frequency map was due composite nature of the test specimen and may represent a softening of the foil-substrate interface.

Single point data taken at the tips of the samples (Figure 7 and Figure 8) while the samples were brought up to temperature and then allowed to cool shows the hysteresis of the beams' modal frequencies. The hysteretic loop shows that for both configurations, the sample's modal frequency dropped with increasing temperature until the SMA treatment reached its austenite finish temperature of $113^{\circ} \mathrm{C}$ due to increasing temperature in the composite beam. At that point the modal frequency increased measurably. As temperature was increased above the austenite finish temperature, the modal frequency slowly decreased in the same fashion it exhibited in the control. A decrease in temperature showed the hysteresis nature of the frequency shift as the samples showed increased modal frequencies until they dropped below approximately $80^{\circ} \mathrm{C}$. Results illustrated an increase of natural frequency for all modes for both full-span and half-span samples. The frequency increase of the full-span sample varied from $3.21 \%$ to $5.62 \%$ for modes $2-5$ (Table 1 ). The frequency increase of the half-span sample varied from $0.80 \%$ to $1.88 \%$ for modes $2-5$ (Table 2 ). While the listed austenite finish temperature for the material was $113^{\circ} \mathrm{C}$, it seems the full effect of the austenite's increased modulus was not seen until temperatures of $140^{\circ} \mathrm{C}+$. The modal frequency after phase transformation is similar in magnitude to what was seen at room temperature, even with the aluminum substrate at an increased temperature. The volume fraction of SMA material for the full length beam was $10.1 \%$. A higher volume fraction of SMA may lead to greater increases in natural frequency.

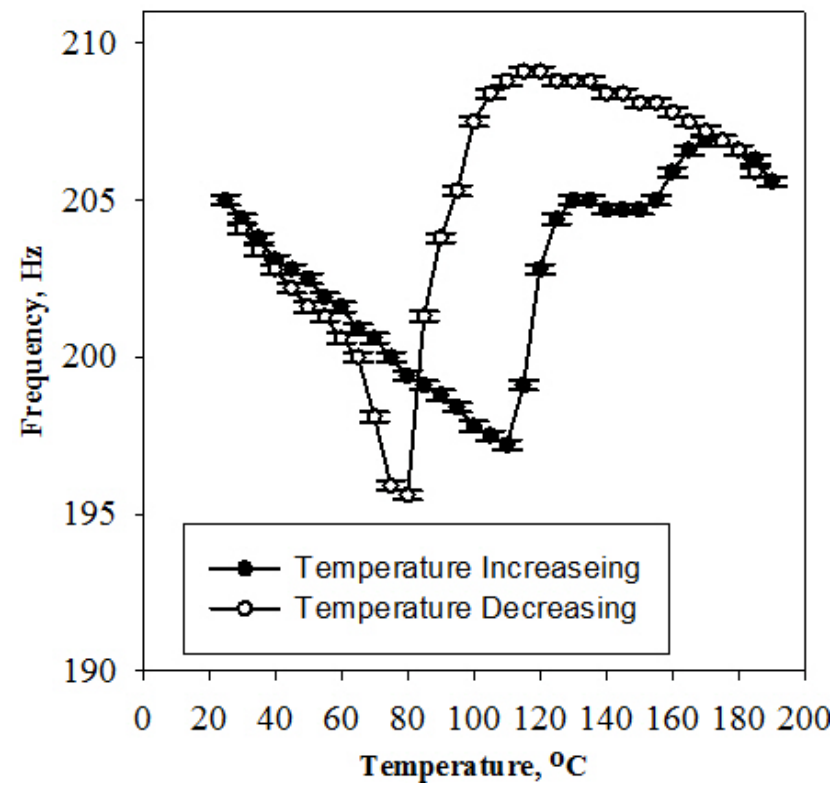

Figure 5. Eigenvalues of full-span test specimen with temperature dependence and measurement uncertainty

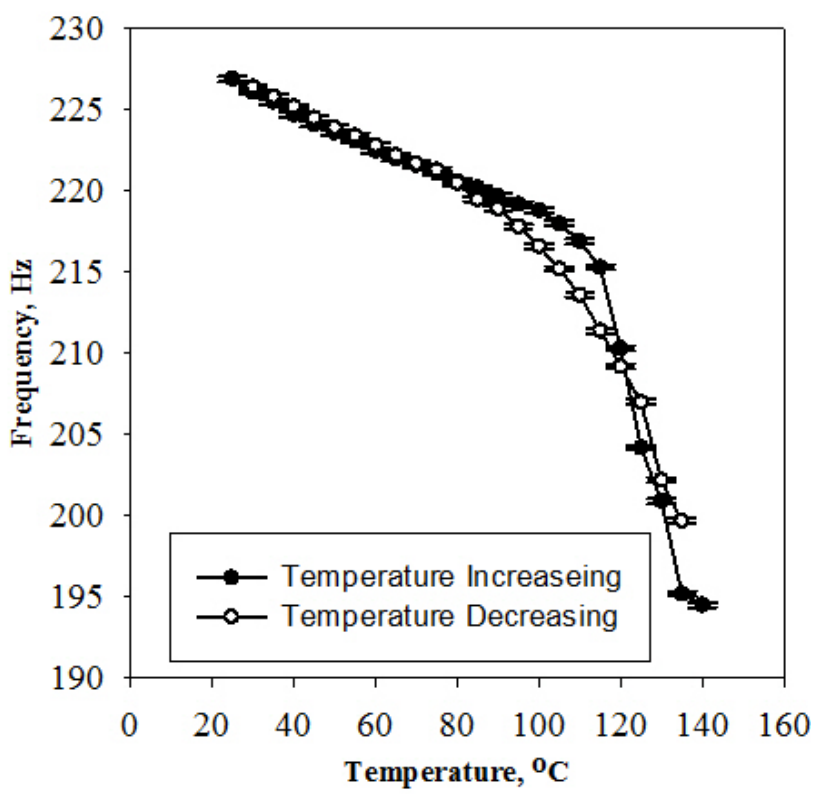

Figure 6. Eigenvalues of aluminum control specimen with Baseline Reference, Aluminum sample

Table 1. Percent change of frequencies and displacements of full-span sample

\begin{tabular}{|c|c|c|c|}
\hline Bending Mode & $\Delta$ Displacement $\left(135^{\circ} \mathrm{C}\right.$ peak to $110^{\circ} \mathrm{C}$ peak $)$ & $\Delta$ Displacement $\left(110^{\circ} \mathrm{C}\right.$ peak to $135^{\circ} \mathrm{C}$ value at $110^{\circ} \mathrm{C}$ peak $)$ & $\Delta$ Frequency \\
\hline 2 & $-3.76 \%$ & $92.70 \%$ & $3.63 \%$ \\
\hline 3 & $3.72 \%$ & $92.47 \%$ & $3.21 \%$ \\
\hline 4 & $77.23 \%$ & $21.53 \%$ & $5.62 \%$ \\
\hline 5 & $-34.07 \%$ & $79.05 \%$ & $3.62 \%$ \\
\hline
\end{tabular}


Table 2. Percent change of frequencies and displacements of half sample

\begin{tabular}{|c|c|c|c|}
\hline Bending Mode & $\Delta$ Displacement $\left(135^{\circ} \mathrm{C}\right.$ peak to $110^{\circ} \mathrm{C}$ peak $)$ & $\Delta$ Displacement $\left(110^{\circ} \mathrm{C}\right.$ peak to $135^{\circ} \mathrm{C}$ value at $110^{\circ} \mathrm{C}$ peak $)$ & $\Delta$ Frequency \\
\hline 2 & $6.20 \%$ & $85.94 \%$ & $1.88 \%$ \\
\hline 3 & $2.41 \%$ & $79.75 \%$ & $1.29 \%$ \\
\hline 4 & $\& 9.14 \%$ & $75.04 \%$ & $0.80 \%$ \\
\hline 5 & $9.78 \%$ & $77.07 \%$ & $1.26 \%$ \\
\hline
\end{tabular}

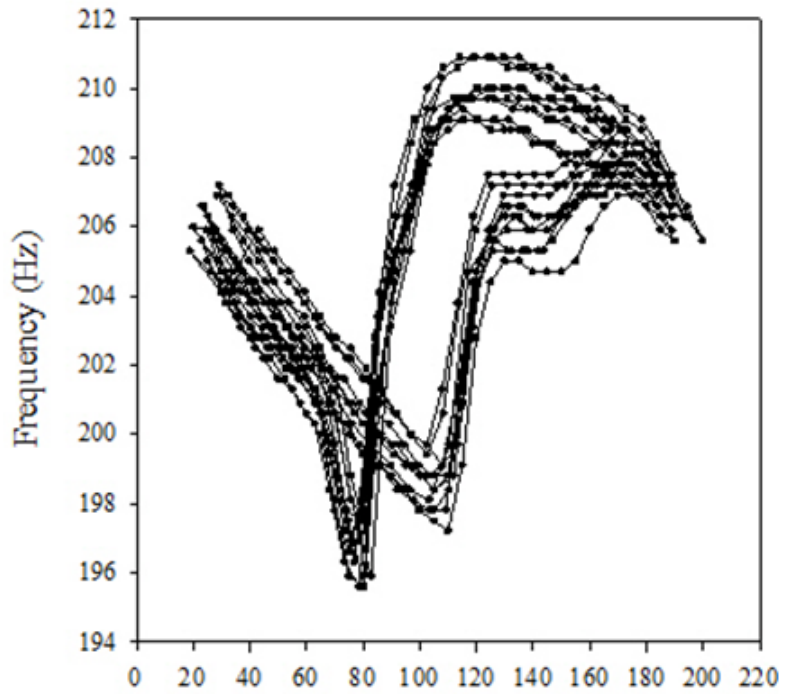

Temperature $\left({ }^{\circ} \mathrm{C}\right)$

(a) Second Bending Mode

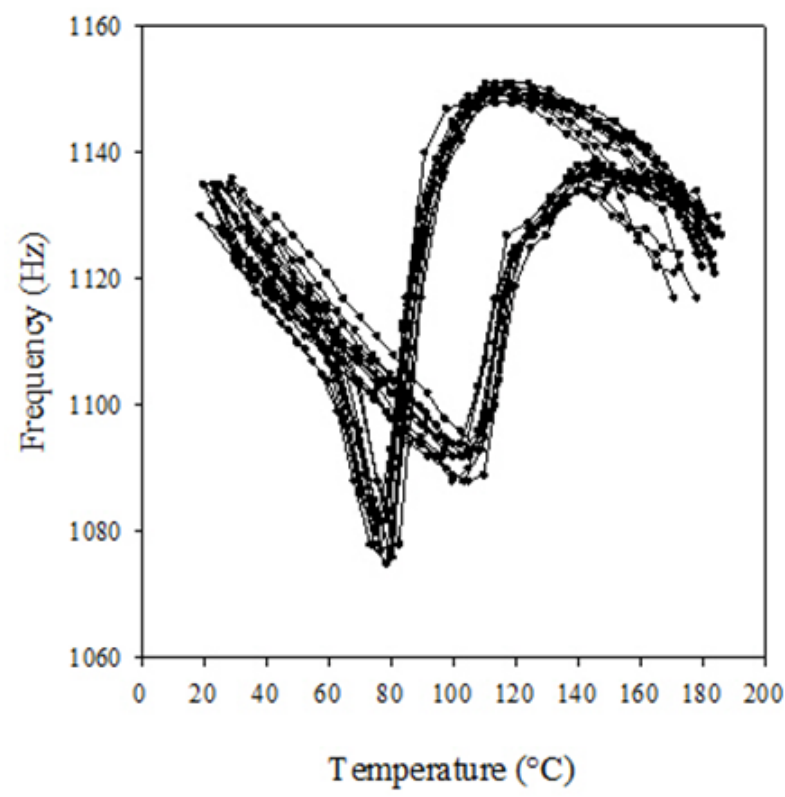

(c) Fourth Bending Mode

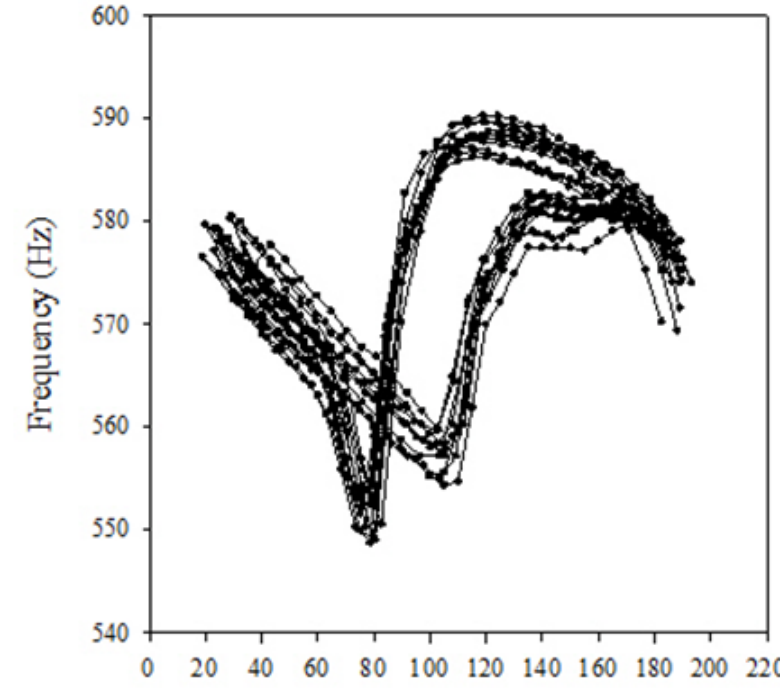

Temperature $\left({ }^{\circ} \mathrm{C}\right)$

(b) Third Bending Mode

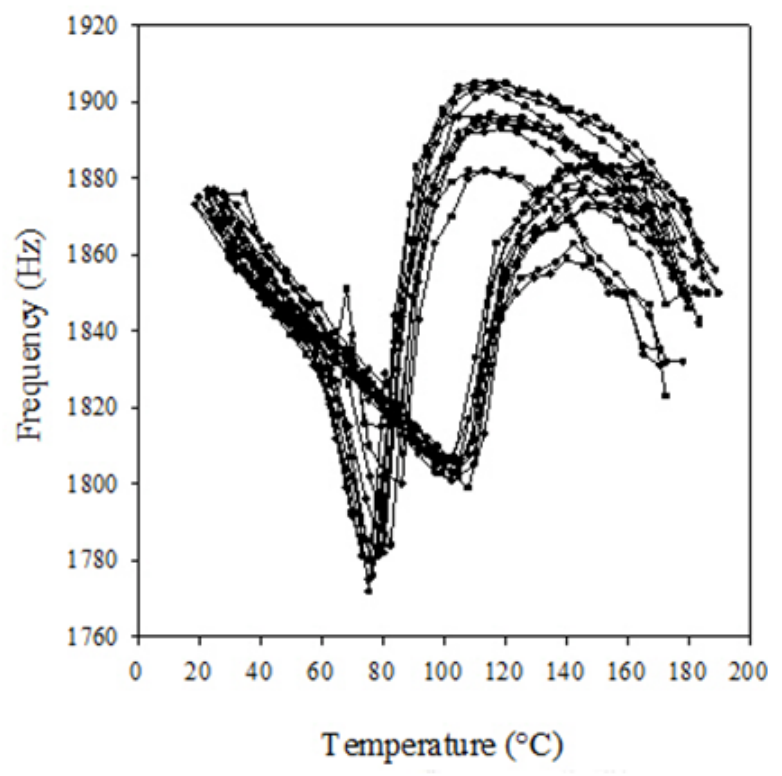

(d) Fifth Bending Mode

Figure 7. Eigenvalues of full-span sample, illustrating the hysteric, nonlinear response with a temperature sweep. Results shown for second bend (a) through fifth bend (d)

After preliminary data was obtained, additional single point scans were completed at the tip of both the full-span and the half-span sample. A total of eleven scans were taken on each sample. During these scans, the SMA surface was brought to $140^{\circ} \mathrm{C}$ for the half sample and $18^{\circ} \mathrm{C}$ for the full-span sample, as this range captured the phase change to austenite and frequency decreased rapidly past these temperatures. This technique resulted in substantially larger responses in frequency shifts. For each scan, the temperature was increased until the modal frequencies started to drop. At this point, the modal frequencies started to behave linearly with increasing temperature. The increase in natural frequencies for these samples were measured as the difference between the highest and lowest natural frequency data point while the sample was being heated. The decrease in natural frequency was similarly measured as the difference between the highest and lowest natural frequency data point while the sample was being cooled. Results for both the full-span and half-span sample are shown in Table 3 
through Table 6 . The percentage change in the tables is shown as a ratio of frequency change over the room temperature frequency of each scan. In the full-span sample, heating frequency change varied from $3.98 \%$ to $4.57 \%$ over bending modes $2-5$. The frequency change while cooling the full-span sample varied from $5.95 \%$ to $6.53 \%$ over these modes. Similarly, in the half sample, heating frequency change varied from $1.50 \%$ to $2.19 \%$ and cooling frequency change varied from $2.36 \%$ to

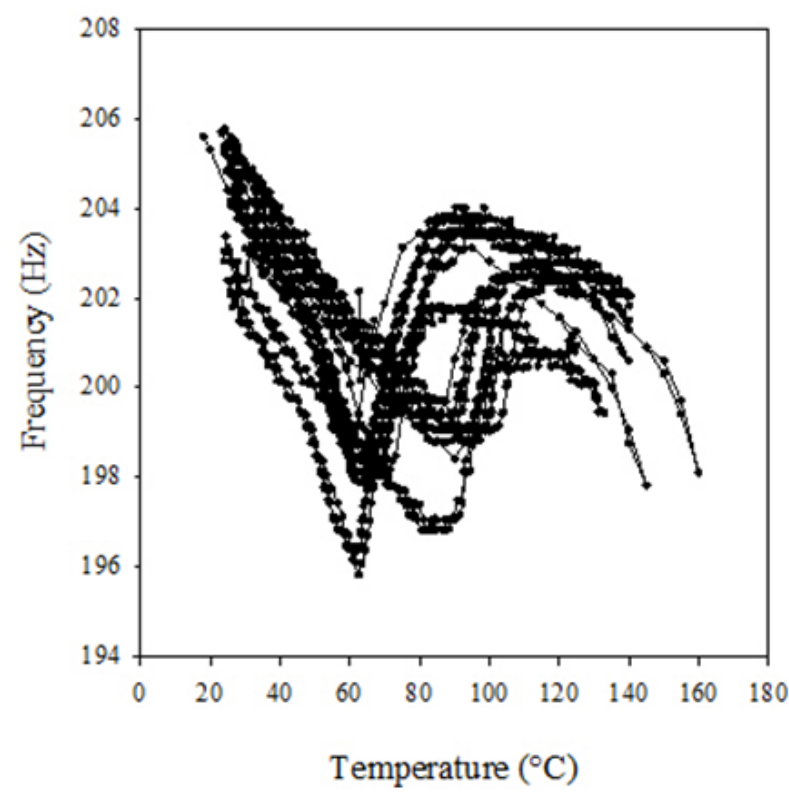

(a) Second Bending Mode

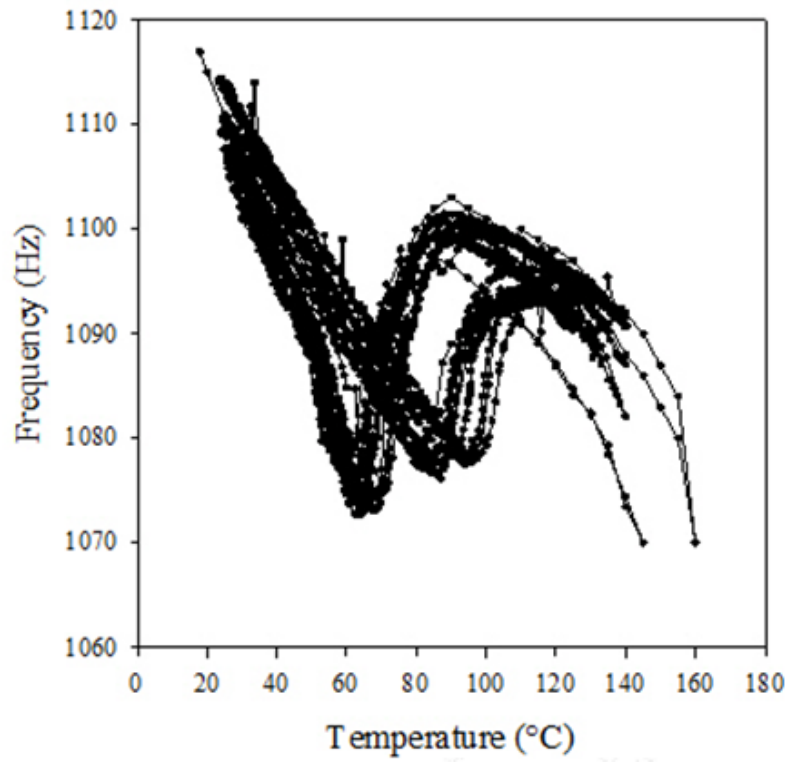

(c) Fourth Bending Mode
$2.90 \%$ over bending modes $2-5$. The precision uncertainty of these values show that they are significant.

The FRF's for both the full-span and half-span samples for the temperatures $110^{\circ} \mathrm{C}$ and $135^{\circ} \mathrm{C}$ are presented in Figure 9 (a)-(b). These temperatures best represented the transition from martensite to austenite. The vibratory response was acquired at blade tip for all modes for consistency, although it is understood that the tip location may not be ideal for all bending modes.

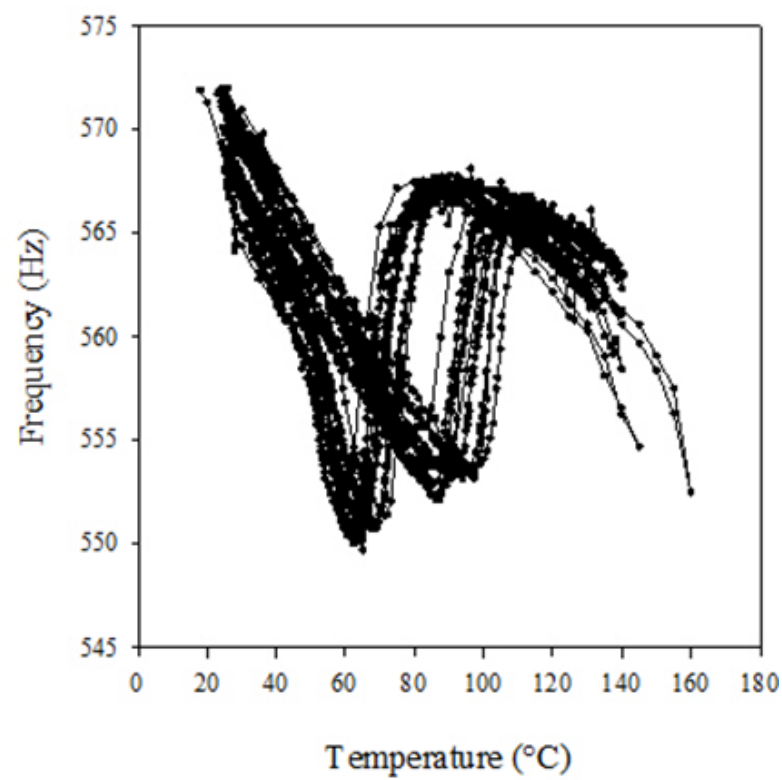

(b) Third Bending Mode

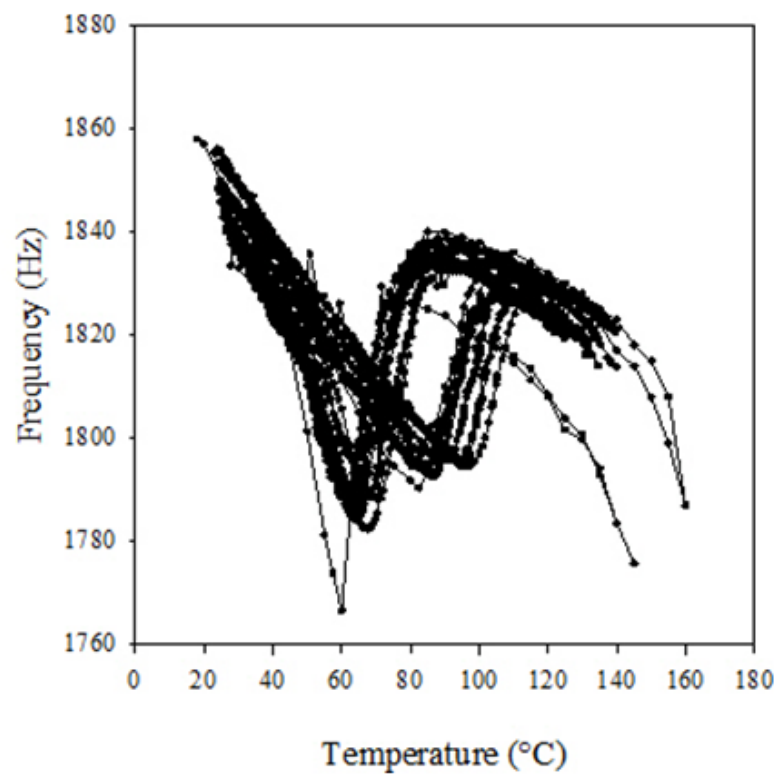

(d) Fifth Bending Mode

Figure 8. Eigenvalues of half-span sample, illustrating the hysteric, nonlinear response with a temperature sweep. Results shown for second bend (a) through fifth bend (d)

Table 3. Repeated Results of Full Sample, Frequency Increase

\begin{tabular}{|c|c|c|c|c|}
\hline & $\begin{array}{c}\Delta \text { Freq. } \\
2^{\text {nd }} \text { Mode }\end{array}$ & $\begin{array}{c}\Delta \text { Freq. } \\
3^{\text {rd }} \text { Mode }\end{array}$ & $\begin{array}{c}\Delta \text { Freq. } \\
4^{\text {th }} \text { Mode }\end{array}$ & $\begin{array}{c}\Delta \text { Freq. } \\
5^{\text {th }} \text { Mode }\end{array}$ \\
\hline Mean (Hz) & 9.43 & 24.29 & 45.36 & 74.45 \\
\hline Precision Uncertainty & 0.316 & 2.38 & 5.57 & 10.7 \\
\hline Mean (\% & 4.57 & 4.20 & 4.00 & 3.98 \\
\hline Precision Uncertainty & 0.154 & 0.411 & 0.492 & 0.569 \\
\hline
\end{tabular}




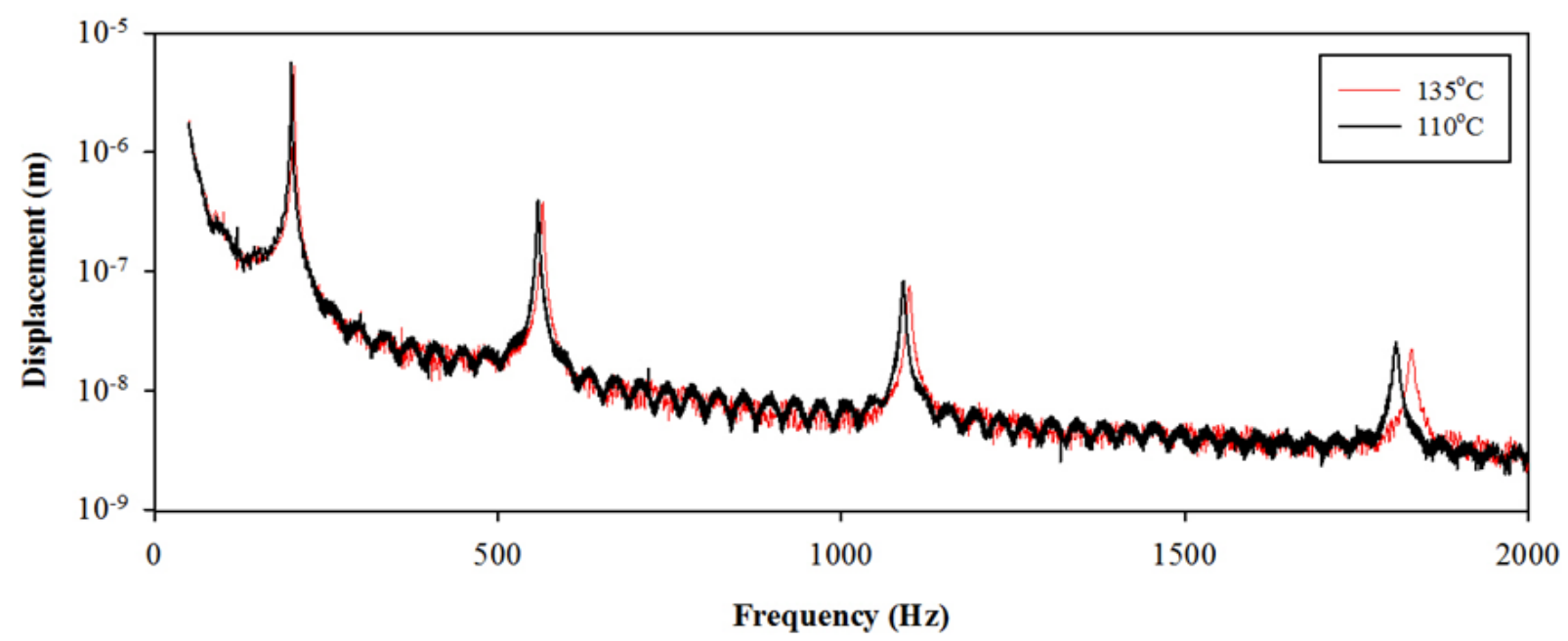

(a) Full-span sample

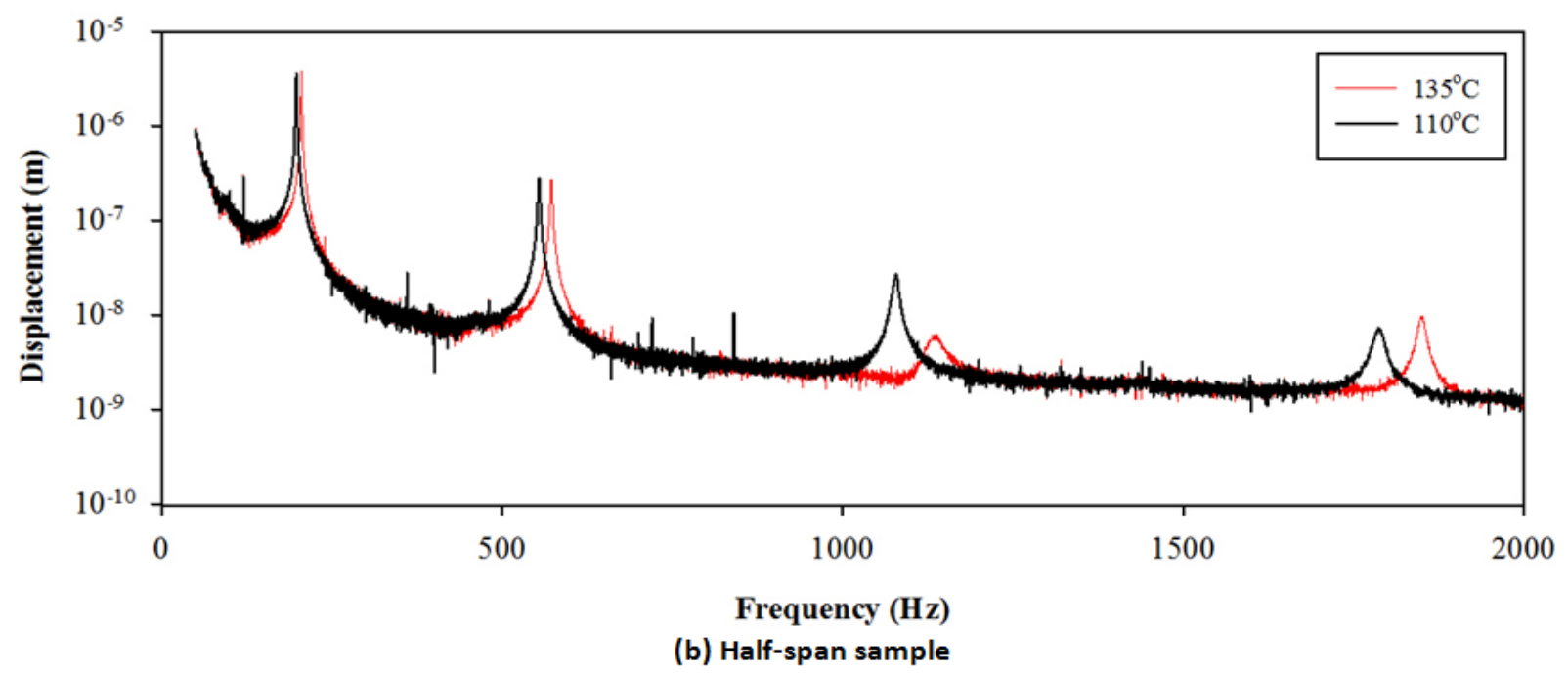

Figure 9. FRF of full-span (a) and half-span (b) samples over 20-2000 $\mathrm{Hz}$ range $110^{\circ} \mathrm{C}$ (black) and $135^{\circ}$ for heating cycle

\subsection{Amplitude Reduction}

Results illustrate that the actuation of the SMA treatments results in a significant reduction in displacement amplitude of the samples at the modal frequency. This reduction in beam tip displacement varied from $21.53 \%$ to $92.7 \%$ (Table 1) for the full-span sample over modes $2-5$ and $75.04 \%$ to $85.94 \%$ (Table 2) for the half sample over modes $2-5$. The reduction in peak modal displacement between actuated and unactuated SMA treatments was also calculated. While for the half sample this reduction varied between $2.42 \%$ and $9.78 \%$, for the full-span sample both the second and fifth modes showed an increase in amplitude. While this is significant, it is believed that the two temperatures selected may not be the optimal temperatures to exhibit the differences in the FRFs between the two phases. Subsequent studies should look at the FRF shape and maximum amplitude at many different temperature points.

\subsection{Node Shift}

A spanwise experimental scan was taken of the halfspan sample. The third bending mode of the sample is shown in Figure 10 in both actuated and unactuated configurations. Both the experimental and computational span wise modal scans show a shift in the location of the 1st node in 3rd bending mode. Experimental and computational shifts of 0.0613 in and 0.0701 in, respectively, were realized. Node shift and amplitude reduction is illustrated in Figure 11.

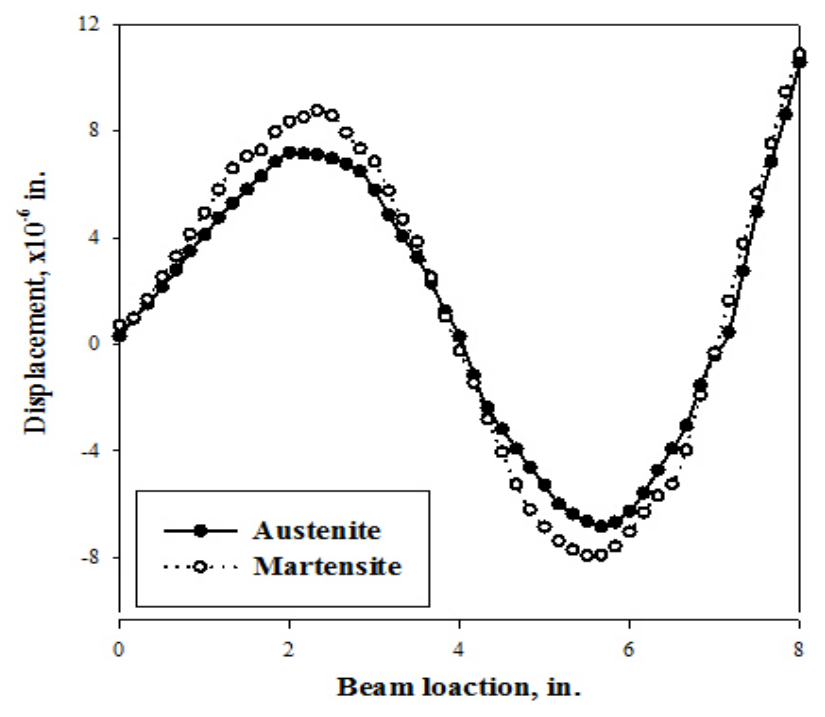

Figure 10. Experimental displacement scan of half sample in austenite and martensite phases 

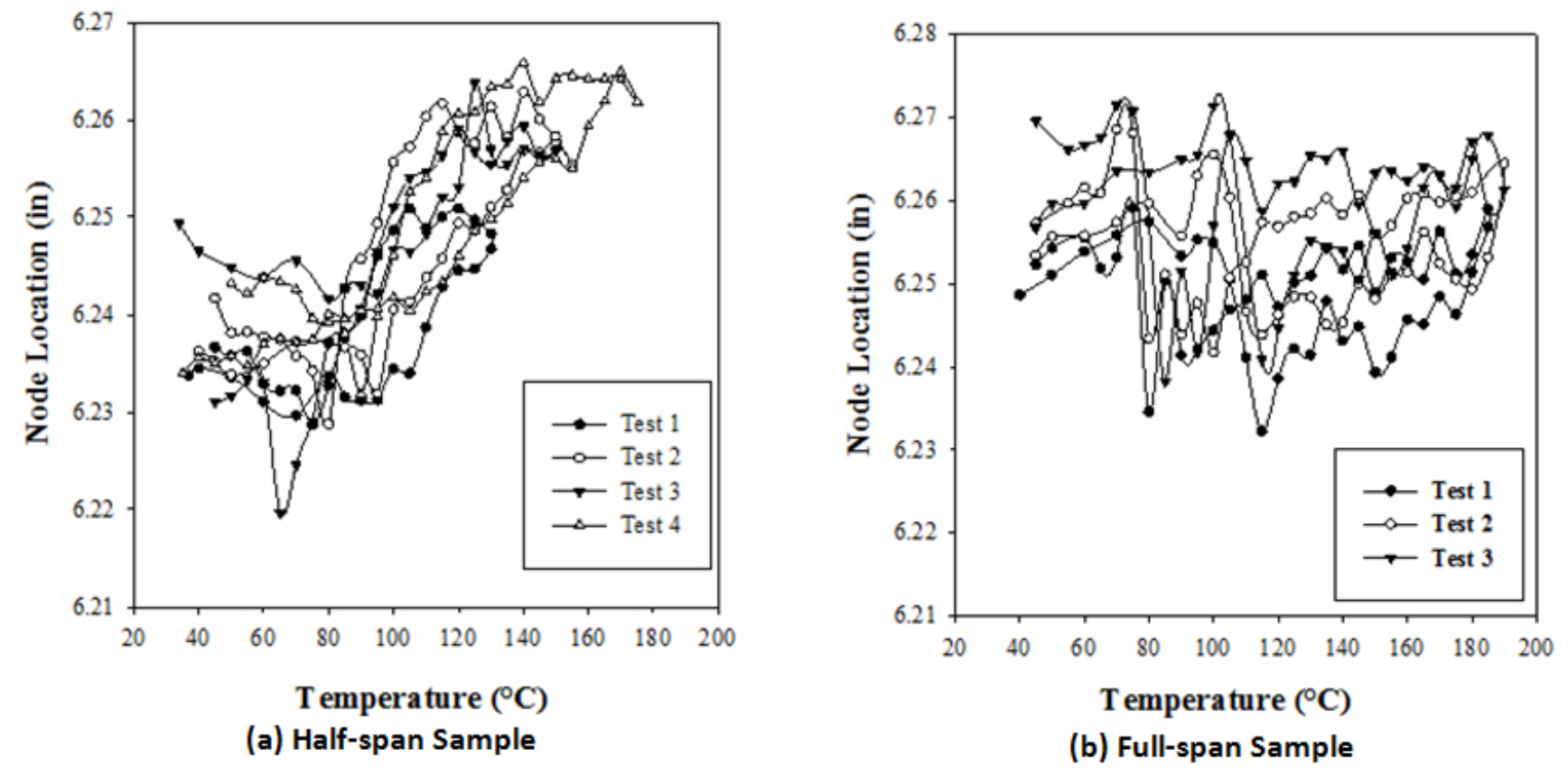

Figure 11. Node location identification at temperatures for (a) half-span and (b) full-span

Table 4. Repeated Results of Full Sample, Frequency Decrease.

\begin{tabular}{|c|c|c|c|c|}
\hline & $\Delta$ Freq. & $\begin{array}{c}\Delta \text { Freq. } \\
3^{\text {rd }} \text { Mode }\end{array}$ & $\begin{array}{c}\Delta \text { Freq. } \\
4^{\text {th }} \text { Mode }\end{array}$ & $\begin{array}{c}\Delta \text { Freq. } \\
5^{\text {th }} \text { Mode }\end{array}$ \\
\hline Mean (Hz) & 13.5 & 37.1 & 70.7 & 111 \\
\hline Precision Uncertainty & 0.530 & 1.96 & 7.12 & 41.6 \\
\hline Mean (\% & 6.53 & $\& 6.41$ & 6.24 & 5.95 \\
\hline Precision Uncertainty & 0.257 & 0.339 & 0.629 & 2.22 \\
\hline
\end{tabular}

Table 5. Repeated Results of Half Sample, Frequency Increase.

\begin{tabular}{|c|c|c|c|c|}
\hline & $\Delta$ Freq. & $\Delta$ Freq. & $\Delta$ Freq. & $\Delta$ Freq. \\
$5^{\text {th }}$ Mode
\end{tabular}

Table 6. Repeated Results of Half Sample, Frequency Decrease.

\begin{tabular}{|c|c|c|c|c|}
\hline & $\Delta$ Freq. & $\Delta$ Freq. & $\Delta$ Freq. & $\begin{array}{c}\Delta \text { Freq. } \\
5^{\text {th }} \text { Mode }\end{array}$ \\
\hline Mean (Hz) & 5.62 & 16.6 & 26.3 & 50.6 \\
\hline Precision Uncertainty & 0.585 & 1.23 & 3.60 & 8.04 \\
\hline Mean (\% & 2.74 & 2.90 & 2.36 & 2.73 \\
\hline Precision Uncertainty & 0.286 & 0.217 & 0.324 & 0.435 \\
\hline
\end{tabular}

\section{Conclusions}

There exists a need to mitigate HCF in both commercial and military jet engines. Novel techniques are necessary to expand the available tools and resources available for design. To this end, SMA topical treatments were designed, fabricated, applied to an aluminum substrate beams, and tested under vibratory conditions in both SMA phase states. Experimental results showed that actuated SMA treatments produced a shift in eigenvalues in both samples, a quantifiable change in vibration amplitude in both samples, and a node shift in the half-span sample. The full-span sample showed an increase in modal frequency, ranging from $3.21 \%$ to $5.62 \%$ over the bending modes analyzed. The half-span sample showed an increase in modal frequency ranging from $0.80 \%$ to $1.88 \%$ over the bending modes analyzed. Highlighting the reduction in amplitude, there was a $85 \%$ reduction in amplitude at second bending with constant excitation frequency with the half sample. Spanwise laser vibrometer scans completed on the half-span sample with and without SMA actuation illustrated a $0.77 \%$ in shift in node location. These results were consistent with previous computational results. Frequency shift tests were repeated a total of eleven times for both test specimens. These tests quantified the change in frequency during both heating and cooling. In the full-span sample, heating frequency change varied from $3.98 \%$ to $4.57 \%$ and cooling 
frequency change varied from $5.95 \%$ to $6.53 \%$ over bending modes 2-5. In the half-span sample, heating frequency change varied from $1.50 \%$ to $2.19 \%$ and cooling frequency change varied from $2.36 \%$ to $2.90 \%$ over bending modes $2-5$. These repeated results show the consistency of modal frequency change during shape memory alloy phase change. Results highlight the potential of shape memory alloys to be used as engineering materials in the design of turbomachinery components with increased high cycle fatigue resistance through quantifiable shifts in frequency, mode shape, and amplitude.

\section{Acknowledgements}

The authors appreciate the contributions of Dr. Jeffrey Brown, Dr. Tommy George, and the Turbine Engine Fatigue Facility (TEFF) at The Air Force Research Laboratory. This work was supported by the Dayton Area Graduate Studies Institute and the Air Force Research Laboratory Ohio Student-Faculty Research Program under agreement RQ6-UA-14-5-AFRL.

\section{References}

[1] Wayman, C., 1993. "Shape memory alloys”. MRS Bulletin.

[2] Wischt, R., and Garafolo, N., 2015. "Variable stiffness technique for turbomachinery using shape memory alloys". Proceedings from the 56th AIAA/ASCE/AHS/ASC Structures, Structural, Dynamics, and Materials Conference.

[3] Wischt, R., and Garafolo, N., 2016. "The development of an active damping and stiffness technique for turbomachinery using shape memory alloys,". Proceedings from the 57th AIAA/ASCE/AHS/ASC Structures, Structural, Dynamics, and Materials Conference.

[4] Nicholas, T., ed., 2006. High Cycle Fatigue: A Mechanics of Materials Perspective. Elsevier Ltd, Oxford UK.

[5] Baz, A., Poh, S., Ro, J., and et al., 1995. "Control of the natural frequencies of nitinol-reinforced composite beams”. Journal of Sound and Vibration, 185.
[6] Lau, K. T., Zhou, L. M., and Tao, X. M., 2002. “Control of natural frequencies of a clamped-clamped composite beam with embedded shape memory alloy wires.”. Composite Structures, 58.

[7] Rezaei DA, H., Kadkhodaei, M., and Nahvi, H., 2012. “Analysis of nonlinear free vibration and damping of a clamped-clamped beam with embed prestrained shape memory wires”. Journal of Intelligent Material Systems and Structures, 23(10).

[8] Liang, C., and Rogers, C. A., 1990. "One-dimensinoal thrmomechancial constituitive relations for shape memory materials”. Journal of Intelligent Material Systems and Structures, 1.

[9] Brinson, L., and Huang, M. S., 1996. "Simplification and comparision of shape memory alloy constiutive models”. Journal of Intelligent Material Systems and Structures, 7(1).

[10] Rajasekhar, M., and Srinivas, J., 2014. “Active vibration control in engine rotors using electromagnetic actuator system”. Journal of Mechanical Design and Vibration, 2(1), pp. 25-30.

[11] Duffy, K., Padula, S. A., and Scheiman, D., 2008. "Damping of high temperature shape memory alloys". In The 15th International Symposium on: Smart Structures and Materials \& Nondestructive Evaluation and Health Monitoring.

[12] Bhaumik, S., Bhakaran, T. A., Rangaraju, R., Venkataswamy, M., Parameswara, M. A., and Krishnan, R. V., 2002. "Failure of turbine rotor blisk of an aircraft engine”. Engineering Failure Analysis, 9(3).

[13] Humbeeck, J. V., 2003. "Damping capacity of thermoeleastic martensite in shape memory alloys". Journal of Alloys and Compounds, 355(1), pp. 58-64.

[14] Noebe, R., D. Gaydosh, D., S. Padula, I., Garg, A., Biles, T., and Nathal, M., 2005. "Properties and potential of two (nipt)ti alloys for use as high-temperature actuator materials”. pp. 364-375.

[15] Noebe, R., S. Padula, I., Bigelow, G., Rios, O., Garg, A., and Lerchl, B., 2006. "Properties of Ni19.5Pd30Ti50.5 high temperature shape memory alloy in tension and compression”. In Proceedings of Smart Structures and Materials 2006: Active Materials: Behavior and Mechanics, Vol. 6170.

[16] S. Padula, I., Noebe, R., Bigelow, G., Culley, G., Stevens, M., Penney, N., Gaydosh, D., Quackenbush, T., and Carpenter, B., 2007. "Development of a htsma-actuated surge control rod for high-temperaute turbomachinery applications”. In 48th AIAA/ASME/ASCE/AHS/ASC Structures, Structural Dynamics, and Materials Conference, no. AIAA 2007-2196.

[17] Klocke, F., Zeis, M., Klimk, A., and Veselovac, D., 2013. "Experimental research on the electrochemical machining of modern titanium- and nickel-based alloys for aero engine components". The Seventeenth CIRP Conference on Electro Physical and Chemical Machining (ISEM), 6, pp. 368-372. 